\title{
Modulation of the ultradian human nasal cycle by sleep stage and body position
}

\author{
Modulação do ciclo nasal humano ultradiano pelo estágio do sono e a posição corporal \\ Richard E. Frye 1,2, Deborah F. Rosin ${ }^{3}$, Adrian R. Morrison ${ }^{4}$, Fidias E. Leon-Sarmiento 1,5, Richard L. Doty ${ }^{1}$
}

\begin{abstract}
Objective: The nasal cycle, which is present in a significant number of people, is an ultradian side-to-side rhythm of nasal engorgement associated with cyclic autonomic activity. We studied the nasal cycle during REM/non-REM sleep stages and examined the potentially confounding influence of body position on lateralized nasal airflow. Methods: Left- and right-side nasal airflow was measured in six subjects during an eight-hour sleep period using nasal thermistors. Polysomnography was performed. Simultaneously, body positions were monitored using a video camera in conjunction with infrared lighting. Results: Significantly greater airflow occurred through the right nasal chamber (relative to the left) during periods of REM sleep than during periods of non-REM sleep ( $p<0.001)$. Both body position ( $p<0.001$ ) and sleep stage $(p<0.001)$ influenced nasal airflow lateralization. Conclusions: This study demonstrates that the lateralization of nasal airflow and sleep stage are related. Some types of asymmetrical somatosensory stimulation can alter this relationship.
\end{abstract}

Keywords: respiratory physiological phenomena; sleep; sleep, REM; activity cicles.

RESUMO

Objetivo: O ciclo nasal é um ritmo ultradiano de lado a lado de ingurgitamento associado com o ciclo da atividade autônoma. 0 objetivo deste estudo foi abordar a questão assim como a relação presente entre o ciclo nasal e os estágios de sono REM/não-REM. Também analisamos a confusão potencial da influência da posição corporal no fluxo de ar nasal. Métodos: Mensuramos o ciclo nasal em seis sujeitos durante um sono de oito horas usando um termistor nasal. Foi realizada uma polissonografia. Simultaneamente, nós monitoramos a posição corporal usando uma câmera de vídeo juntamente com luzes infravermelhas. Resultados: Um fluxo de ar maior ocorreu através da cavidade nasal direita durante as fases de sono REM do que nos períodos de sono não-REM ( $p<0,001)$. Assim como a posição corporal $[F(2.2340)=86,99$, $p<0,001]$ e o estágio de sono $[F(1.2340)=234.82, p<0,001]$ influenciaram a lateralização do fluxo de ar nasal. Conclusões: Este estudo evidencia que a lateralização do fluxo de ar nasal e o estágio do sono estão relacionados. Alguns tipos de estimulação somatosensitiva assimétrica podem alterar esta relação.

Palavras-chave: fenômenos fisiológicos respiratórios; sono; sono REM; ciclos de atividade.

The classic nasal cycle, which is present in significant number of people, is a 40-minute to four-hour ultradian rhythm of side-to-side nasal mucosal engorgement that results in modulation of nasal airflow. The alternating rhythmicity associated with the nasal cycle decreases with age ${ }^{1,2}$. This cycle has been demonstrated in both laboratory animals ${ }^{3}$ and humans ${ }^{4}$. The nasal cycle is determined by the autonomic tone of capacitance vessels located in the deep portion of the mucosal lining of the nasal turbinates and septum. A hypothalamic and/ or medullary regulator is believed to control the asymmetric lateralization of the autonomic tone $e^{5}$, although the effects of this regulator can be overridden by other systems associated with asymmetric peripheral nerve stimulation. For example, localized pressure to a single axilla results in an ipsilateral increase and contralateral decrease in nasal resistance ${ }^{6}$. Lateral recumbency leads to decongestion of the upper-most nasal cavity ${ }^{7}$, regardless of the phase of the nasal cycle.

\footnotetext{
${ }^{1}$ University of Pennsylvania, Smell and Taste Center, Department of Otorhinolaryngology: Head and Neck Surgery, Philadelphia, PA, USA;

${ }^{2}$ University of Arkansas for Medical Sciences, Department of Pediatrics, Little Rock, AR, USA;

3 John F. Kennedy Medical Center Section of ENT, Department of Surgery, Edison, NJ, USA;

4 University of Pennsylvania, School of Veterinary Medicine, Department of Animal Biology, Philadelphia, PA USA;

${ }^{5}$ Unicolciencias/Universidad Nacional, Mediciencias Research Group, Bogota, Colombia.
}

Correspondence: Fidias E. Leon-Sarmiento; University of Pennsylvania, Smell and Taste Center, 5 Ravdin Pavilion, Perelman School of Medicine 3400 Spruce Street, Philadelphia, PA 19104, USA; E-mail: feleones@gmail.com

Conflict of interest: There is no conflict of interest to declare.

Support: This research was supported by USAMRAA W81XWH-09-1-0467, and by the Eleanor Dana Center for Sleep Disorders, University of Pennsylvania, Philadelphia, USA.

Received 12 January 2016; Accepted 24 August 2016. 
Asymmetries in integrated electroencephalographic (EEG) activity have been shown to be correlated with the nasal cycle. Werntz et al. ${ }^{8}$ found, in 19 subjects, a significant negative correlation between the left:right differences in the EEG and the left:right differences in nasal airflow (median $r=-0.85)$. Proportionately, more airflow occurred through the right nasal chamber than through the left nasal chamber when left hemispheric integrated EEG activity reached its maximum relative to the right. However, the relationship between the nasal cycle and components of the EEG and sleep stage is not clear. Goldstein et al. ${ }^{9}$ found that the EEG activity is larger in the left hemisphere during REM sleep periods than during non-REM sleep periods (and vice versa), a finding that would suggest that relative airflow should be greater on the right than on the left during REM episodes. In contrast to this prediction, however, are findings from a number of studies that have used Fourier or period analysis. Such studies found that non-REM sleep periods are associated with a more symmetric EEG across hemispheres, whereas REM sleep periods are associated with a more asymmetric EEG across hemispheres, and that the direction of the asymmetry may not be consistent ${ }^{10,11,12}$.

In the present study we addressed the issue as to whether a relationship is present between the nasal cycle and REM/non-REM sleep stages. We also examined the potentially confounding influence of body position ${ }^{13,14}$ on the measure of nasal airflow.

\section{METHODS}

\section{Subjects}

Three male and three female healthy subjects (mean = 29.9 years, $\mathrm{SD}=12.9$ ) participated in a 12-hour recording session. The absence of major airway abnormality was determined by an upper airway examination. No subject reported a history of allergic reactions, sleep disorders, or breathing problems. All had normal left, right, and total nasal resistance values ${ }^{15}$, as measured by anterior rhinomanometry. None of the subjects were under treatment for any medical disorder, or taking medication at the time of testing. All subjects provided informed written consent and the study was approved by the Office of Regulatory Affairs of the University of Pennsylvania, United States.

\section{Data collection}

The participants reported to the sleep laboratory in the late afternoon (usually around 5:30 p.m.). Grass silver disk electrodes, filled with electrolyte gel, were attached to face and scalp areas, which were previously degreased. Each subject was then placed in a hospital bed for four hours of waking recording to facilitate adaptation to the testing environment. Lights were turned out in the test room at 10 p.m., at which time the subjects were allowed to sleep. Polysomnographic recording was performed with a Grass recorder (Grass Instrument Co., Quincy; Mass). Bilateral EEGs were recorded from the parietal, frontal, and occipital lobes (Figure 1). Two electrodes taped to the chin and two electrodes attached to the outer canthus of each eye provided measurement of electromyography (EMG) and electrooculography (EOG), respectively. Nasal thermistors were uniformly placed below the outer edge of each nostril and secured with tape. The body movements of subjects were recorded by a video camera in conjunction with infrared lighting.

At the start of the test session, each subject was asked to cover one nostril and breathe normally. The nasal thermistor amplifier was then adjusted to produce a waveform half the maximum limit of the range of the wave recorded. The same procedure was then repeated for the opposite naris. In this way, the transducers were calibrated to the airflow of the subject's nares at the start of the testing period. The amplifier gain was adjusted to allow proper measurement of waveforms; a correction factor was later applied to correct for this adjustment. In one subject, a thermistor moved from its position early in the evening and required repositioning and recalibration. In this case, the data from the first portion of the night was not included in the analysis.

Sleep stage was determined using Rechtschaffen and Kales' system ${ }^{16}$. The EEGs were scored by a licensed sleep researcher who regularly scored EEGs for the clinical sleep laboratory within the Hospital of the University of Pennsylvania. The sleep researcher did not know the hypotheses of the study. Epochs containing transition periods or extensive artifacts that precluded the ability to stage the epoch reliably were not included in the analysis. Body position was classified as left lateral, right lateral, or supine. The prone body position was never observed for any subject,

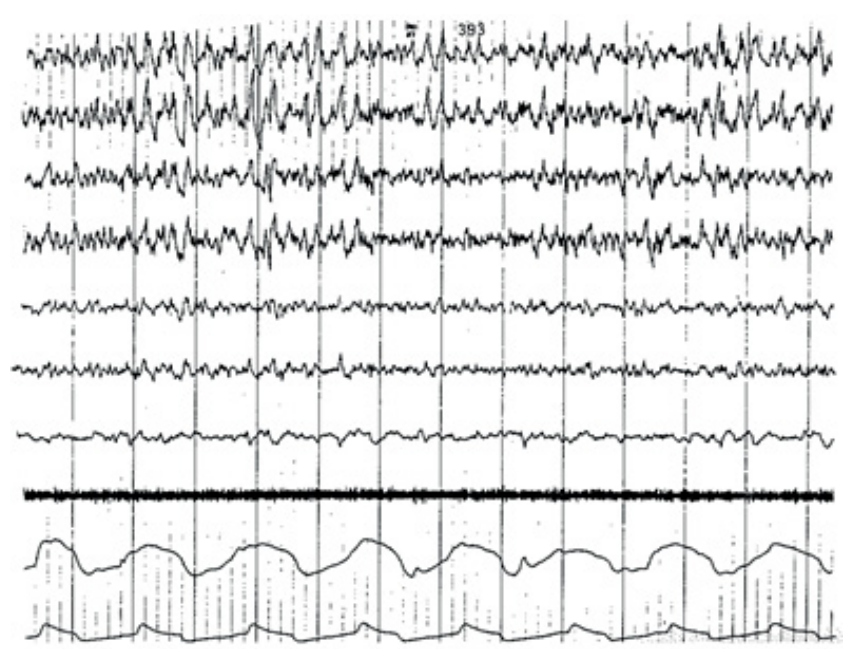

Figure 1. Polysomnographic recordings from a male subject during non-REM sleep. The tracings from top to bottom are EEG F3-A1, F4-A2, P3-A1, P4-A2, P3-01, and P4-O2, EOG, EMG, right airflow, and left airflow. 
probably because the arrangement of electrode leads made this position uncomfortable for the subject.

To determine nasal airflow, the amplitude of one representative nasal airwave from each nostril was measured from the recording for every minute of study. Correction factors were applied to the airwave amplitude measurement to correct for differences in amplifier gain when necessary. To correct for the non-linear output of the nasal thermistors, the data were linearized by a natural log function ${ }^{17}$. The symmetry of the transformed data (i.e., that it was indeed normal distribution) was confirmed by experiential data analysis methodology $^{18}$. From these data, two dependent measures were calculated. The first measure represented relative asymmetry of nasal airflow and was derived by calculating the percentage of total airflow through the right naris from the transformed data [i.e., ([ln(right naris amplitude)] / (ln(right naris amplitude $)+\ln ($ left naris amplitude $)] * 100]^{19}$. The second measure was the absolute value of the difference between the transformed left and right naris values [i.e., abs[ $\ln ($ left naris amplitude) - $\ln$ (right naris amplitude)]. Both of these measures were then standardized for each subject by converting the subject's data points to z-scores.

\section{Data analysis}

To evaluate the influences of body position and sleep stage on nasal airflow, a weighted two-way (sleep stage by body position) ANOVA was applied to the dependent measures. This model allowed us to remove bias due to unequal number of observations between subjects. Sleep stages were dichotomized as non-REM (which included sleep stages 1, 2, 3 and 4) and REM. Differences among body positions were compared using one degree-of-freedom post-hoc orthogonal F-Tests. The Bonferroni correction was applied to the resulting $\mathrm{p}$-values to correct for inflated alpha due to multiple comparisons.

\section{RESULTS}

Both body position and sleep stage were found to influence nasal airflow lateralization [body position: $\mathrm{F}(2,2340)=86.99$, $\mathrm{p}<0.001$; sleep stage $\mathrm{F}(1,2340)=234.82, \mathrm{p}<0.001]$. In addition, these two variables significantly interacted [body position by sleep stage interaction: $\mathrm{F}(2,2340)=26.06, \mathrm{p}<0.001$ ] The adjusted mean percentage of the airflow through the right nostril during non-REM and REM sleep stages for the three body positions are presented in Table 1 . The number of data points within the REM and non-REM periods upon which this analysis was based is shown in Table 2.

Multiple one-degree-of-freedom F-tests were used to compare the differences among body positions. These post-hoc tests revealed that all positions differed from one another [right vs. left: $\mathrm{F}(1,2340)=173.44, \mathrm{p}<0.001$; right vs. supine $\mathrm{F}(1,2340)=37.56, \mathrm{p}<0.001$; left vs. supine: $\mathrm{F}(1,2340)=52.01$, $\mathrm{p}$ $<0.001$ ]. As can be seen in Table 1, airflow was proportionally greater in the right nasal chamber when a subject was in the left lateral body position. The degree of this effect was less when a subject was in the supine position, and least when in the right lateral position. The sleep-stage-by-body-position interaction reflected the fact that the airflow lateralization due to sleep stage was largest in the supine position and smallest in the right lateral position (Figure 2).

In order to establish whether airflow symmetry related to sleep stage similar to its relationship to the $\mathrm{EEG}^{10-12}$,

Table 1. Mean (standard error of the mean) percentage of total airflow through the right nasal chamber as estimated by the analysis of variance model for non-REM and REM sleep stages.

\begin{tabular}{lccc}
\hline Variable & $\begin{array}{c}\text { Non-REM } \\
\text { Sleep }\end{array}$ & REM sleep & $\begin{array}{c}\text { Overall for } \\
\text { body position }\end{array}$ \\
\hline Right side & $50.4(0.72)$ & $51.7(0.44)$ & $51.0(0.42)$ \\
Supine & $52.7(0.45)$ & $60.2(0.57)$ & $56.4(0.27)$ \\
Left side & $54.3(0.40)$ & $58.8(0.35)$ & $56.7(01.37)$ \\
$\begin{array}{l}\text { Overall for } \\
\text { sleep stage }\end{array}$ & $52.5(0.31)$ & $56.9(0.28)$ & $54.8(0.21)$ \\
\hline
\end{tabular}

REM: Rapid Eye Movement.

Table 2. Number of data points during REM, non-REM, and waking following the onset of sleep periods for each subject during the test period.

\begin{tabular}{lcccc}
\hline \multirow{2}{*}{$\begin{array}{l}\text { Subject } \\
\text { number }\end{array}$} & \multicolumn{4}{c}{ Sleep stage } \\
\cline { 2 - 5 } & Non-REM & REM & Waking or artifact & Total \\
\hline 1 & 288 & 98 & 140 & 526 \\
\hline 2 & 294 & 62 & 110 & 466 \\
\hline 3 & 424 & 16 & 56 & 496 \\
\hline 4 & 350 & 58 & 122 & 530 \\
\hline 5 & 302 & 84 & 102 & 488 \\
6 & 330 & 40 & 124 & 494 \\
\hline
\end{tabular}

REM: Rapid Eye Movement.

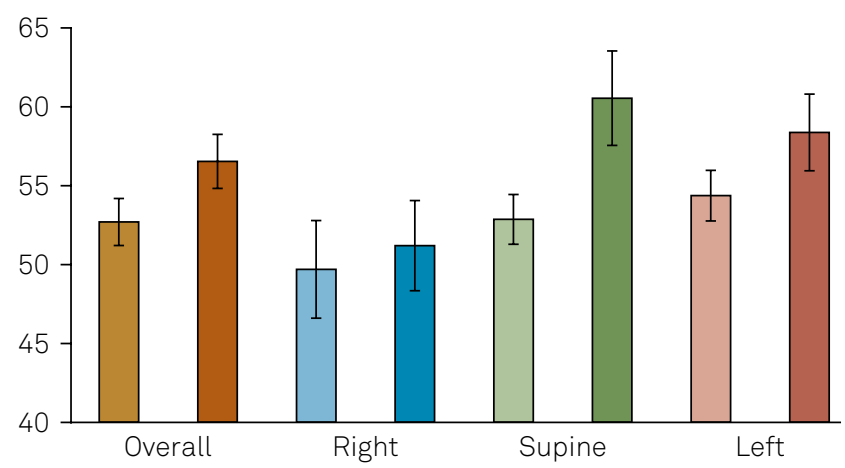

Figure 2. Percentage (Y-axis) of total airflow through the right nasal chamber for three body positions during REM (full color bars) and non-REM sleep (light color bars) states. Note the linear relationship between body position and the dependent measure during non-REM sleep. This relationship was not clear during REM sleep, most likely resulting in the significant sleep stage by body position interaction. 
we determined if there was a difference in absolute airflow that occurred during REM and non-REM sleep. Although sleep stage was not related to the difference in absolute airflow across nostrils, body position was related to this measure [sleep stage: $\mathrm{F}(1,2340)=0.23, \mathrm{p}>0.60$; body position $\mathrm{F}(2,2340)=46.06$, $\mathrm{p}<0.001$ ] (Table 3). Multiple one-degree-of-freedom F-tests revealed a significant difference between the right lateral position and the left lateral and supine positions, but did not reveal a significant difference between the left lateral and supine positions [right lateral vs. left lateral $\mathrm{F}(1,2340)=54.64, \mathrm{p}<0.001$; right lateral vs. supine $\mathrm{F}(1,2340)=81.87$, $\mathrm{p}<0.001$; left lateral vs. supine $\mathrm{F}(1,2340)=2.59, \mathrm{p}>0.10]$. However, a significant sleepstage-by-body-position interaction was found $[\mathrm{F}(1,2340)=29.53$, $\mathrm{p}<0.001]$. This reflects the fact that the magnitude of the absolute difference measure was greater during the non-REM than during the REM sleep when subjects were in the right lateral or supine positions, whereas the magnitude of this measure was greater during the REM than the non-REM sleep stage when subjects were in the left lateral position (Table 3).

Since REM sleep is associated with higher frequency EEG than non-REM sleep ${ }^{16}$, it is conceivable that a relationship exists between brain wave frequency and nostril dominance. We found only a weak relationship, confined to the supine position, between sleep stage ranked in terms of brain wave frequency and airflow lateralization (Spearman $r=0.254$ ). Thus, brain wave frequency probably does not account for a significant part of the sleep stage and nasal cycle relationship.

\section{DISCUSSION}

This study demonstrates that the lateralization of nasal airflow and sleep stage are related. In fact, greater airflow was found to occur though the right nasal chamber during REM sleep. This study confirms that the side of maximal nasal airflow is influenced by body position, with the most airflow occurring through the uppermost nasal cavity ${ }^{19}$. In addition, the data support the notion that the nasal cycle is not an artifact of asymmetrical body position or other environmental factors ${ }^{20,21,22}$. Since no asymmetries in body pressure and

Table 3. Adjusted mean (standard error of the mean) absolute difference between the logged left and right naris airflow measurements for non-REM and REM sleep stages by each body position.

\begin{tabular}{lccc}
\hline Variable & $\begin{array}{c}\text { Non-REM } \\
\text { sleep }\end{array}$ & REM sleep & $\begin{array}{c}\text { Overall for } \\
\text { body position }\end{array}$ \\
\hline Right side & $1.08(0.008)$ & $0.97(0.008)$ & $1.02(0.006)$ \\
Supine & $0.176(0.006)$ & $0.64(0.005)$ & $0.70(0.004)$ \\
\hline $\begin{array}{l}\text { Left side } \\
\text { Overall for } \\
\text { sleep stage }\end{array}$ & $0.73(0.004)$ & $0.87(0.002)$ & $0.80(0.003)$ \\
\hline
\end{tabular}

REM: Rapid Eye Movement. posture were present when subjects were in the supine position, the airflow from this position may be most representative of the endogenous nasal cycle ${ }^{23}$.

The statistical interaction between sleep stage and body position was likely due to the differential influence of body position on the physiological expression of the nasal cycle during different stages of sleep. As can be seen from Table 1, the association between the nasal cycle and sleep stage was greatest when subjects were in the supine position. The smaller magnitude of the sleep stage and nasal cycle relationship when the subjects were in the right or left lateral body position is likely due to asymmetric stimulation of pressure receptors located in superficial ventral, dorsal, and lateral aspects of the pelvic and pectoral girdles and thoracic wall, and deep aspects of the intercostal spaces and parietal pleura ${ }^{24}$. The reflex arc resulting from such stimulation results in increased vasoconstriction in the inferior nasal cavity and decreased vasoconstriction in the superior nasal cavity. Others have suggested that asymmetric body pressure induces a sustained inhibition of the nasal cycle ${ }^{25}$. Our data suggest that the first of the mentioned effects had a greater influence in this study.

A body position by sleep stage interaction was found for the absolute left:right airflow difference measure. This interaction arose from the fact that there was no consistent relationship between the absolute airflow difference and sleep stage across the three body positions. An examination of the sleep stage mean demonstrates that, overall, any effect from sleep stage on the absolute difference in the airflows is opposite to the EEG effect reported by Armitage et al. ${ }^{10}$. Thus, our data suggest it is unlikely that a relationship exists between the absolute difference in airflow from the two sides of the nose and sleep stage.

The results of the present study clarify and expand observations of previous studies. Alexiev and Roth ${ }^{13}$ failed to find an overall relationship between sleep stage and nasal airflow in an eight-hour test session in four normal subjects, although an increase in airflow through the right naris was observed during the third REM sleep cycle. Since body position data were not collected, their inconsistent results may have arisen from the influence of asymmetric stimulation of pressure receptors. Hudgel and Robertson ${ }^{14}$ investigated which factors, other than body position, influenced the lateralization of nasal airflow during sleep. Unfortunately, the nares were only classified in terms of their position relative to the lateral body position (i.e., superior or inferior), rather than their anatomic body side (i.e., right or left). Thus, it was not possible for them to analyze left-right changes in nasal airflow. Haight and $\mathrm{Cole}^{24}$, while providing evidence for the nasal cycle during sleep, were unable to demonstrate a clear relationship between sleep stage and nasal cycle phase since measurements were made after the patients were aroused from sleep. Kimura et al. ${ }^{22}$ found an association between the reversal of the nasal cycle and sleep stage in $69 \%$ of 16 subjects studied. None of the reversals occurred in the slow-wave sleep. Due to the limited statistical information provided by 
the authors, a more elaborated discussion on their findings cannot be done. Rohrmeier et al. ${ }^{23}$ studied the nasal cycle in 20 healthy subjects. Long-term rhinoflowmetry was measured during wakefulness and sleep. With these findings, these researchers concluded that shifts in body position during sleep modulate the nasal cycle $(\mathrm{p}<0.01)$. Since polysomnography was not performed, it is difficult to ascertain which sleep stage related to their findings.

It is unknown whether the REM/non-REM rhythm influences the nasal cycle directly or if a common central oscillator influences both the nasal cycle and the $\mathrm{REM} /$ non-REM rhythm ${ }^{26}$. A central oscillator hypothesis is supported by studies suggesting that the REM/non-REM rhythm is derived from a common 90-minute central rhythm known as the basic rest-activity cycle (BRAC) $)^{27}$. Since the BRAC has been proposed to drive asymmetric autonomic rhythms associated with the relative tonus of blood vessels of both the nasal mucosa and the cerebral hemispheres, it is possible that the mechanism underlying the BRAC rhythm is responsible for the synchronization of nasal mucosal engorgement and asymmetric hemispheric brain activity. Although the REM/non-REM cycle is strongly associated with asymmetric brain activity during sleep, the precise mechanism that relates these rhythms has not been defined.

In conclusion, this study demonstrates a relationship between the rhythms of the nasal cycle and sleep stage; however, the precise association between these rhythms and the cerebral hemisphere EEG rhythm remains enigmatic. Werntz et al. ${ }^{8}$ assumed that a single oscillator drove cyclic EEG activity; however, other studies suggest that the two hemispheres may be driven by separate oscillators, possibly located in the hypothalamus, having slightly different periods ${ }^{28}$. Such a phenomenon could explain the discrepancies in the cyclic relationship between the two hemispheres reported in the literature. Separate control of turbinate engorgement on either side of the nose probably does not exist since this endogenous cycle is robust; moreover, the nasal cycle has been documented under various conditions ${ }^{4}$ and during various times of the day $y^{5}$. The other possibility is that homeostatic regulation by the hypothalamus that characterizes REM ${ }^{29}$ gets disrupted. Future research is needed to assess this hypothesis.

\section{References}

1. Mirza N, Kroger H, Doty RL. Influence of age on the 'nasal cycle'. Laryngoscope. 1997;107(1):62-6. doi:10.1097/00005537-199701000-00014

2. Shilenkova VV, Kozlov VS. [A nasal cycle in healthy children]. Vestn Otorinolaringol. 2008;(1):11-6. Russian.

3. Eccles R. The domestic pig as an experimental animal for studies on the nasal cycle. Acta Otolaryngol. 1978;85(5-6):431-6. doi:10.3109/00016487809121472

4. Saroha D, Bottrill I, Saif M, Gardner B. Is the nasal cycle ablated in patients with high spinal cord trauma?. Clin Otolaryngol Allied Sci. 2003;28(2):142-5. doi:10.1046/j.1365-2273.2003.00679.x

5. Eccles R. The central rhythm of the nasal cycle. Acta Otolaryngol. 1978;86(5-6):464-8. doi:10.3109/00016487809107526

6. Davies AM, Eccles R. Reciprocal changes in nasal resistance to airflow caused by pressure applied to the axilla. Acta Otolaryngol. 1985;99(1-2):154-9. doi:10.3109/00016488509119158

7. Haight JJ, Cole P. Reciprocating nasal airflow resistances. Acta Otolaryngol. 1984;97(1-2):93-8. doi:10.3109/00016488409130968

8. Werntz DA, Bickford RG, Bloom FE, Shannahoff-Khalsa DS. Alternating cerebral hemispheric activity and the lateralization of autonomic nervous function. Hum Neurobiol. 1983;2(1):39-43.

9. Goldstein L, Stoltzfus NW, Gardocki JF. Changes in interhemispheric amplitude relationships in the EEG during sleep. Physiol Behav. 1972;8(5):811-5. doi:10.1016/0031-9384(72)90289-2

10. Armitage R, Hoffmann R, Loewy D, Moffitt A. Variations in period-analysed EEG asymmetry in REM and NREM sleep. Psychophysiology. 1989;26(3):329-36. doi:10.1111/j.1469-8986.1989.tb01928.x

11. Moffitt A, Hoffmann R, Wells R, Armitage R, Pigeau R, Shearer J. Individual differences in pre- and post-awakening correlates of dream reports following awakening from different stages of sleep. Psychiatr J Univ Ott. 1982;7:111-25.

12. Pivik RT, Bylsma F, Busby K. Sawyer S. Interhemispheric EEG changes: relationship to sleep and dreams in gifted adolescents. Psychiatr Univ Ottawa. 1982;7:56-76.
13. Alexiev AD, Roth B. Some peculiar changes in the pattern of respiration connected with REM sleep: a preliminary report. Electroencephalogr Clin Neurophysiol. 1978;44(1):108-11. doi:10.1016/0013-4694(78)90110-4

14. Hudgel DW, Robertson DW. Nasal resistance during wakefulness and sleep in normal man. Acta Otolaryngol. 1984;98(1-2):130-5. doi:10.3109/00016488409107544

15. Pallanch JF, McCaffrey TV, Kern EB. Normal nasal resistance. Otolaryngol Head Neck Surg. 1985;93:778-85.

16. Rechtschaffen A, Kales A. A Manual of standardized terminology, techniques and scoring system for sleep stages of human subjects. Washington, DC: Public Health Service; 1968.

17. Allocca JA, Stuart A. Transducers: theory and application. Reston, VA: Reston; 1984.

18. Behrens JT. Principles and procedures of exploratory data analysis. Psychol Methods. 1997;2(2):131-60. doi:10.1037/1082-989X.2.2.131

19. Rao S, Potdar A. Nasal airflow with body in various positions.J Appl Physiol. 1970;28(2):162-5.

20. Haight JS, Cole P. Is the nasal cycle an artifact? The role of asymmetrical postures. Laryngoscope. 1989;99(5):538-41. doi:10.1288/00005537-198905000-00013

21. Lal D, Gorges ML, Ungkhara G, Reidy PM, Corey JP. Physiological change in nasal patency in response to changes in posture, temperature, and humidity measured by acoustic rhinometry. Am J Rhinol. 2006;20(5):456-62. doi:10.2500/ajr.2006.20.2939

22. Kimura A, Chiba S, Capasso R, Yagi T, Ando Y, Watanabe $S$ et al. Phase of nasal cycle during sleep tends to be associated with sleep stage. Laryngoscope. 2013;123(8):2050-5. doi:10.1002/lary. 23986

23. Rohrmeier C, Schittek S, Ettl T, Herzog M, Kuehnel TS. The nasal cycle during wakefulness and sleep and its relation to body position. Laryngoscope. 2014;124(6):1492-7. doi:10.1002/lary.24546

24. Haight JS, Cole P. Unilateral nasal resistance and asymmetrical body pressure.J Otolaryngol Suppl. 1986;16 1-31. 
25. Brown TH, McAfee DA. Long-term synaptic potentiation in the superior cervical ganglion. Science. 1982;215(4538):1411-3. doi:10.1126/science.6278593

26. Atanasov AT, Dimov PD. Nasal and sleep cycle: possible synchronization during night sleep. Med Hypotheses. 2003;61(2):275-7. doi:10.1016/S0306-9877(03)00169-5

27. McPartland RJ, Kupfer DJ. Rapid eye movement sleep cycle, clock time and sleep onset. Electroencephalogr
Clin Neurophysiol. 1978;45(2):178-85. doi:10.1016/0013-4694(78)90002-0

28. Gordon HW, Stoffer DS, Lee PA. Ultradian rhythms in specialized cognitive function. J Clin Exp Neurophysiol. 1990;12:40.

29. Lanfranchi PA, Fradette L, Gagnon JF, Colombo R, Montplaisir J. Cardiac autonomic regulation during sleep in idiopathic REM sleep behavior disorder. Sleep. 2007;30(8):1019-25. 